\title{
KETRAMPILAN KERAJINAN ACCESSORIES UNTUK MODAL KEWIRAUSAHAAN MASYARAKAT, KELURAHAN JATCEMPAKA, KECAMATAN PONDOK GEDE, KAB. BEKASI (USAHA PEMBEKALAN MASYARAKAT UNTUK ANTISIPASI MASALAH TKI
}

\author{
Drs. Eko Tri Rahardjo \\ Fakultas Ilmu Sosial Universitas Negeri Jakarta
}

\begin{abstract}
ABSTRAK
Melalui kegiatan pengabdian kepada masyarakat ini diharapkan akan memberikan pelatihan ketrampilan yang dapat dimanfaatkan untuk mencari tambahan pendapatan bagi masyarakat di daerah padat penduduk di Jakarta Timur dengan membuat berbagai barang kerajinan.

Sasaran dalam kegiatan ini adalah ibu rumahtangga dan para remaja yang berminat. Kegiatan ini dilaksanakan di luar jam kerja atau pada saat sore hari. Instruktur diambil dari para pengrajin yang telah berpengalaman dalam pembuatan dan pemasaranya. Kegiatan pelatihan terdiri dari $90 \%$ praktik dan sisanya berbagi pengalaman tentang cara mendapatkan bahan, prosesing dan peluang pemasaranya.

Pelatihan ini sifatnya pemberian motivasi bahwa untuk mengembangkan kreativitas, inovasi, dan kemauan, seseorang dapat membantu dirinya sendiri mendapatkan pendapatan lebih, dengan cara membuat berbagai kerajinan hasil kreatifitasnya yang pada akhirnya dapat menumbuhkan kemandirian perekonomian ibu rumah tangga.
\end{abstract}

1. PENDAHULUAN

A. ANALISIS SITUASI

1. Identifikasi Masalah

Pendidikan nasional yang berdasarkan Pancasila dan Undang-Undang Dasar Negara Republik Indonesia Tahun 1945 berfungsi mengembangkan kemampuan dan membentuk watak serta peradaban bangsa yang bermartabat dalam rangka mencerdaskan kehidupan bangsa, bertujuan untuk mengembangkan potensi peserta didik agar menjadi manusia yang beriman dan bertaqwa kepada Tuhan Yang Maha Esa, berakhlak mulia, sehat, berilmu, cakap, kreatif, mandiri, dan menjadi warga negara yang demokratis serta bertanggungjawab. Untuk pengembangan fungsi tersebut pemerintah menyelengarakan satu sistem pendidikan nasional sebagaimana tercantum dalam Pemberlakuan UU Republik Indonesia No. 20 Tahun 2003 tentang Sistem Pendidikan Nasional.

Pendidikan dan hidup layak merupakan hak seluruh bangsa Indonesia, pendidikan dapat dijangkau melalui proses pembelajaran, dan pembelajaran tidak dibatasi oleh waktu dan usia. Belajar dan pembelajaran berlangsung sepanjang hayat sejauh hal itu diperlukan. Manusia belajar sesuai dengan kebutuhannya. Tujuan pembelajaran yang mencakup belajar afeksi, belajar kognisi dan belajar ketrampilan semua membawa manfaat sesuai dengan porsinya. Masing-masing tujuan pembelajaran tersebut akan memberikan kontribusi kepada kehidupan individu sesuai dengan kapasitas dan kebutuhannya.

Di kehidupan sekitar kita, tidak semua anggota masyarakat dapat menempuh pendidikan sampai jenjang tinggi. Terdapat sekelompok masyarakat yang hidup dengan bekal pendidikan minimum. Hal ini disebabkan karena banyak hal yang antara lain ketiadaan biaya, waktu dan lainnya yang intinya adalah pada ketiadaan kesempatan. Kondisi seperti ini juga terjadi di lingkungan permukiman padat penduduk di Jakarta Timur, dimana terdapat sekelompok masyarakat dengan ijasah relatif rendah. Para anggota masyarakat ini sukar untuk meningkatkan penghasilan dan taraf hidup mereka. Bekal ijasah yang rendah dan ketiadaan biaya dan kurangnya kemampuan memanfaatkan kesempatan menjadi salah satu beban dan kendala kemajuan kehidupan ekonomi mereka.

Sehubungan dengan hal di atas maka diperlukan suatu upaya yang secara riil dapat dilakukan 
dan berdampak langsung terhadap kemampuan mereka dalam meningkatkan kehidupan perekonomiannya. Salah satu upaya tersebut adalah dengan memberikan ketrampilan tambahan dan memberikan hasil yang nyata, cepat dan langsung dapat dimanfaatkan dan dirasakan hasilnya.

Berdasarkan analisis situasi yang telah diuraikan, maka masalah yang dapat diidentifikasikan adalah sebagai berikut:

a. Para anggota masyarakat umumya taraf perekonomianya relatif rendah.

b. Jenjang pendidikan rendah sehingga sukar meningkatkan pendapatanya.

c. Masyarakat mengalami kendala dalam meningkatkan jenjang pendidikan karena alasan ekonomi dan kesempatan.

d. Diperlukan ketrampilan tambahan untuk mendapatkan peluang meningkatkan perekonomian dan kesejahteraan.

e. Perekonomian yang terbatas ini membatasi masyarakat dalam memperoleh pendidikan dan ketrampilan.

f. Diperlukan upaya untuk memberikan ketrampilan tanpa mereka berhenti bekerja dan tanpa mengeluarkan biaya.

\section{Rumusan Masalah}

Dari berbagai permasalahan yang dapat diidentifikasi, maka masalah yang dirumuskan dalam program ini adalah: Upaya meningkatkan ketrampilan masyarakat tanpa mereka harus berhenti bekerja dan tanpa mengeluarkan biaya, untuk memberi peluang mendapatkan penghasilan tambahan.

\section{Manfaat Kegiatan}

a. memberikan ketrampilan tambahan.

b. memberikan peluang meningkatkan pendapatan.

c. menumbuhkan kemandirian.

d. meningkatkan produktivitas

\section{KAJIAN PUSTAKA}

\section{A. KETRAMPILAN DAN PENDAPATAN}

Pendapatan yang dimaksud dalam kegiatan ini adalah penghasilan yang didapat seseorang dari hasil bekerja atau mengasilkan produk tertentu. Menurut Safir Senduk (2000), penghasilan seseorang dipengaruhi oleh faktor-faktor: pendidikan, pekerjaan, umur, harta, tempat tinggal, keberuntungan, bakat, kerjakeras, koneksi dan diskriminasi.

1. Pendidikan, orang yang berpendidikan tinggi cenderung menghasilkan banyak uang, hal ini menyebabkan orang cenderung menganggap bahwa orang akan berpenghasilan tinggi setelah menempuh pendidikan tinggi. Namun demikian yang benar adalah bahwa pendidikan bisa membantu seseorang untuk memperoleh penghasilan tinggi. Namun demikian terdapat potensi bahwa orang berpendidikan tinggi berpeluang lebih besar karena umumnya memiliki wawasan yang lebih luas.

2. Pekerjaan, orang yang pekerjaanya menggunakan pikiran biasanya lebih banyak menghasilkan uang dibandingkan dengan orang yang pekerjaanya menggunakan tenaga.

3. Umur, orang yang berumur lebih tua biasanya mendapatkan penghasilan lebih tinggi dibandingkan yang usianya lebih muda karena faktor pengalaman dan lama bekerja.

4. Harta, kaitan harta dengan penghasilan ialah bahwa seseorang bisa saja memiliki investasi sehingga dapat menambah penghasilan selain dari upah.

5. Tempat tinggal, standar gaji dan upah serta biaya hidup dapat memengaruhi perbedaan penghasilan walaupun dalam pekerjaan dan level yang sama tetapi beda tempat tinggal, misalnya beda kota atau di kota dengan kota lain yang beda peraturan.

6. Keberuntungan, faktor ini tidak dapat diprediksi tetapi tetap menjadi variabel yang dipertimbangkan, misalnya fluktuasi perusahaan menentukan bonus karyawan.

7. Bakat, bakat menentukan mutu pekerjaan sehingga dapat memengaruhi penghasilan seseorang.

8. Kerja Keras, kerja keras merupakan salah satu faktor yang menentukan produktifitas, selain dari promosi jabatan. 
9. Koneksi, koneksi dapat menentukan penghasilan. Misalnya dengan koneksi mendapatkan penghasilan sampingan atau mendapat tambahan pekerjaan yang menghasilkan uang.

10. Diskriminasi, diskriminasi ini dapat menyangkut gender atau kesukuan. Misalnya pria dan wanita bekerja dalam level yang sama tetapi pria digaji lebih tinggi, sama-sama sebagai konsultan tetapi konsultan asing digaji lebih tinggi. (http://www.perencanakeuangan.com/ files/Faktor Penghasilan.html diambil tanggal 4/30/2012 jam 11:26)

Sehubungan dengan uraian di atas maka yang dapat diupayakan untuk meningkatkan penghasilan pada kondisi pegawai sebagai orang yang berpendidikan rendah, sebagai orang yang berpekerjaan rendah, dan berharta tidak banyak, serta tempat tinggal yang kurang kondusif untuk mencari tabahan. Caranya adalah dengan mengoptimalkan keberuntungan, bakat, kerjakeras, dan melalui koneksi yang legal. Mengoptimalkan keberuntungan dapat dilakukan dengan memberikan bekal ketrampilan sehingga memperoleh peluang lebih banyak, sedangkan bakat adalah diupayakan mengoptimalkan bakat dengan memberikan berbagai macam ketrampilan sehingga dimungkinkan untuk dipilih sampai akhirnya muncul salah satu bakat yang terpendam dan dapat dioptimumkan, kerja keras dapat diupayakan melalui etos kerja yang meningkat.

Adapun koneksi yang legal maksudnya adalah memberikan perhatian khusus dengan memilih secara sengaja kepada mereka yang benar-benar membutuhkan untuk diberikan peluang yang lebih besar.

\section{B. METODE PEMBELAJARAN KETRAMPILAN}

Dalam proses pembelajaran, banyak sekali metode dan media yang dapat dipergunakan. Menurut Edgar Dale proses pembelajaran dengan cara mengalami sendiri akan mempunyai dampak yang lebih baik dibandingkan dengan apabila sekedar mendengarkan. Pada gambar di bawah ini ditunjukan tentang efektifitas pengalaman belajar. Bagian paling atas dari kerucut ini adalah bagian yang paling sempit memberikan kontribusi pengalaman belajar, sedangkan bagian paling bawah menunjukan pengalaman belajar yang hasilnya paling luas. (Edgar Dale dalam Oemar Hamalik, 1982).

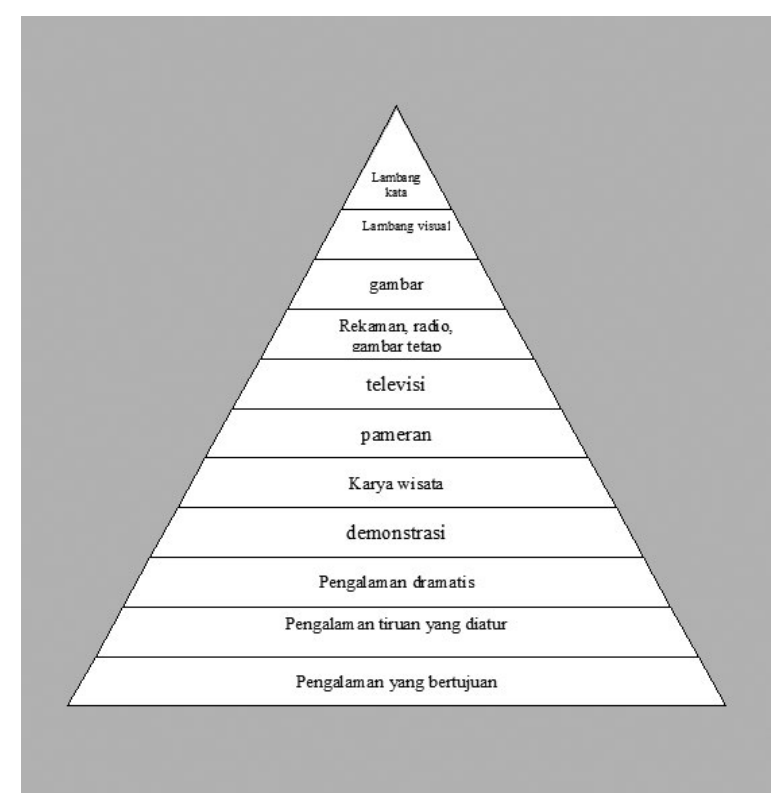

Gambar 1. Diagram efektifitas pengalaman belajar (Edgar Dale dalam Oemar Hamalik, 1976)

Berdasarkan pada gambar di atas terlihat bahwa pembelajaran ketrampilan akan baik jika diberikan secara langsung melibatkan aktivitas peserta. Sementara itu penyerapan informasi sehingga menjadi suatu hasil belajar juga mengalami suatu proses belajar. Proses belajar dikatakan baik apabila peserta mampu mengungkapkan kembali atau melakukan kembali apa yang telah diajarkanya. Dalam hal ini maka suatu hasil yang berupa produk merupakan manifestasi dari hasil pengungkapan kembali apa yang dipelajari sebelumnya.

Dalam revisi teori Bloom tentang tujuan pembelajaran, Lorin W. Anderson dan David R. Krathwohl membuat taksonomi pembelajaran menjadi seperti pada tabel berikut ini: 


\begin{tabular}{|l|l|l|l|l|l|l|}
\hline \multirow{2}{*}{$\begin{array}{c}\text { Dimensi } \\
\text { Pengetahuan }\end{array}$} & \multicolumn{5}{|c|}{ DIMENSI PROSES KOGNITIF } \\
\cline { 2 - 7 } & Mengingat & Memahami & Mengaplikasikan & Menganalisis & Mengevaluasi & Mencipta \\
\hline Faktual & & & & & & \\
\hline Konseptual & & & & & & \\
\hline Prosedural & & & & & & \\
\hline Metakognisi & & & & & & \\
\hline
\end{tabular}

Berdasarkan taksonomi di atas, apabila seseorang diberi pelajaran tertentu maka hasil akhirnya adalah menciptakan sesuatu. Dalam hal ketrampilan membuat produk maka dapat dikategorikan sebagai pengetahuan faktual yang nyata tampak, dapat dilihat, dipegang dan dirasakan, sehingga hasil akhir dari bahan mentah dapat dicipta menjadi sesuatu yang bernilai lebih tinggi. Uraian ini jika memandang belajar melalui jalur pemanfaatan kognitif, dari ranah psikomotor menurut Dave (1967) proses belajar dapat berjalan melalui langkah sebagai berikut:

\begin{tabular}{|l|l|l|l|l|}
\hline PENIRUAN & PENGGUNAAN & KETEPATAN & PERANGKAIAN & NATURALISASI \\
\hline $\begin{array}{l}\text { Meniru gerak } \\
\text { yang diamati } \\
\text { atau diajarkan }\end{array}$ & $\begin{array}{l}\text { Menggunakan } \\
\text { konsep untuk } \\
\text { melakukan gerak }\end{array}$ & $\begin{array}{l}\text { Melakukan } \\
\text { gerak dengan } \\
\text { teliti dan benar }\end{array}$ & $\begin{array}{l}\text { Merangkaikan } \\
\text { berbagai gerakan } \\
\text { secara berkesinambungan }\end{array}$ & $\begin{array}{l}\text { Melakukan gerak } \\
\text { secara wajar } \\
\text { dan efisien }\end{array}$ \\
\hline
\end{tabular}

Untuk selanjutnya menurut Aida Idris (1982 /1983) seseorang akan lebih berhasil belajar bila yang dipelajarinya itu bertalian dengan apa yang diperlukannya dalam kehidupan sehari-hari, yang berarti bahwa ia mengetahui secara jelas tujuan belajarnya. Agar tercapai keberhasilan belajarnya, faktor minat pun harus diperhitungkan. Minat seseorang terhadap apa yang dipelajarinya merupakan salah satu faktor yang memungkinkan konsentrasi belajarnya. Karena ia menaruh minat terhadap apa yang dipelajarinya itu maka akan timbul padanya kegairahan belajar, sehingga ia giat belajar. Oleh karena minat itu perlu ditimbulkan, dan minat belajar itu timbul apabila terdapat hubungan antara orang yang belajar dan yang dipelajarinya. Berdasarkan uraian di atas, berarti bahwa pada seseorang itu harus ada berbagai kemampuan sehubungan apa yang dipelajarinya, seperti menghargai, memahami, menikmati, dan menggunakan apa yang dipelajarinya itu. Menurut Dale (dalam Oemar Hamalik, 1976) pengalaman langsung atau keterlibatan langsung akan mempengaruhi memori dalam pembelajaran. Sehubungan dengan hal tersebut secara teoritis metode pembelajaran langsung mempunyai konstribusi yang baik dalam proses pembelajaran.

\section{MATERI DAN METODE}

A. Tujuan dan Manfaat Kegiatan

\section{Tujuan Kegiatan}

Tujuan dari kegiatan ini dapat diuraikan sebagai berikut:

a. memberikan ketrampilan tambahan membuat berbagai barang kerajinan dengan bahan yang murah dan mudah didapatkan.

b. memberikan peluang meningkatkan pendapatan dengan berbagi pengalaman dengan instruktur sekaligus sebagai pengrajin.

c. menumbuhkan kemandirian perekonomian ibu rumah tangga

\section{B. MANFAAT KEGIATAN}

Melalui kegiatan pengabdian kepada masyarakat ini diharapkan akan memberikan ketrampilan yang dapat dimanfaatkan untuk mencari tambahan pendapatan. 
Kegiatan ini bermanfaat bagi peserta untuk memperoleh materi pembuatan berbagai barang kerajinan. Dengan pelatihan ini peserta mendapat manfaat contoh dan ide pembuatan berbagai kerajinan, sehingga diharapkan mereka dapat mengembangkan inspirasinya untuk membuat sendiri, menjadi inovatif dan memanfaatkanya untuk mencari tambahan pendapatan setelah ikut pelatihan ini.

DOI : https://doi.org/1

Pelatihan ini sifatnya pemberian motivasi bahwa dengan sedikit kreativitas, inovasi, dan kemauan, seseorang dapat membantu dirinya sendiri mendapatkan pendapatan lebih, dengan cara membuat berbagai kerajinan hasil kreatifitasnya.

\section{REALISASI PEMECAHAN MASALAH}

Pemecahan masalah dilakukan dalam bentuk pelatihan pengenalan bahan, pembuatan berbagai barang kerajinan, penggalian ide inovatif, dengan memancing ide dari para peserta untuk memanfaatkan bahan sederhana dengan cara berpikir sederhana namun kreatif.

\section{KHALAYAK SASARAN}

Sasaran dalam kegiatan ini adalah ibu rumahtangga dan para remaja yang berminat. Kegiatan g/10.2100்日isdiładedsitadkanosi luar jam kerja atau pada saat sore hari. Instruktur diambil dari para pengrajin yang telah berpengalaman dalam pembuatan dan pemasaranya.

\section{E. WAKTU DAN TEMPAT KEGIATAN}

Kegiatan dimulai dengan penyusunan proposal pada bulan Juli 2016 dan direncanakan selesai pada bulan September 2016, lokasi dipilih daerah padat penduduk di Jakarta Timur.

Jadwal kegiatan disusun sebagai berikut:

\begin{tabular}{|c|l|c|c|c|c|}
\hline NO. & \multicolumn{1}{|c|}{ KEGIATAN } & JULI & AGUST & SEPT & OKT \\
\hline 1 & Penyusunan Proposa & XXXXX & & & \\
\hline 2 & Pengajuan Proposal & & XXXX & & \\
\hline 3 & Kegiatan Pelatihan & & & XXXX & \\
\hline 4 & Penyusunan Laporan & & & & XXXX \\
\hline
\end{tabular}

\section{F. METODE PENERAPAN}

Kegiatan terdiri dari $90 \%$ praktik dan sisanya berbagi pengalaman tentang cara mendapatkan bahan, prosesing dan peluang pemasaranya. Sesi satu display beberapa contoh barang kerajinan yang sudah dibuat dan akan dibuat.
Sesi kedua demonstrasi pembuatan dan langsung praktik dengan bahan yang disediakan. Peserta diminta mencoba mempraktekan yang diajarkan dan meneruskan jika belum jadi, atau bagi yang sudah jadi atau bisa membuat diminta untuk mengembangkan model lain.

Kegiatan ini direncanakan meliputi 8 kali pertemuan dengan jadwal sebagai berikut:

\begin{tabular}{|c|l|c|c|}
\hline MINGGU KE & MATERI KEGIATAN & NARA SUMBER & WAKTU \\
\hline 1 & Pengenalan bahan & Pengrajin & 30 menit \\
\hline 2 & Pembuatan Kerajinan & Pengrajin & 180 menit \\
\hline 3 & Pemasaran & Pengrajin & 30 menit \\
\hline 4 & Latihan Mandiri & Pengrajin & $\begin{array}{l}\text { Disesuaikan dengan } \\
\text { waktu peserta }\end{array}$ \\
\hline
\end{tabular}


Jadwal kegiatan di atas dapat lakukan perubahan sesuai dengan kondisi dan kebutuhan peserta.

\section{G. BIAYA YANG DIBUTUHKAN}

\begin{tabular}{|c|l|r|r|}
\hline NO & \multicolumn{1}{|c|}{ KOMPONEN } & BIAYA & JUMLAH (Rp.) \\
\hline 1. & Bahan ketrampilan & 15 org $\times 2 \times$ Rp.100.000,- & $3.000 .000,-$ \\
\hline 2. & Honor instruktur luar UNJ & 4 org $\times 2 \times$ Rp.300.000,- & $2.400 .000,-$ \\
\hline 3. & Transport instruktur & 4 org $\times 2 \times$ Rp.100.000,- & $800.000,-$ \\
\hline 4. & Pembelian Bahan dan peralatan & & $2.600 .000,-$ \\
\hline 5. & Honor Tenaga Kebersihan & 4 org $\times 8 \times$ Rp.100.000,- & $3.200 .000,-$ \\
\hline 6. & Transport Panitia & 20 org $\times 8 \times$ Rp. $10.000,-$ & $1.600 .000,-$ \\
\hline 7. & Konsumsi & & $1.000 .000,-$ \\
\hline 8. & Lain-lain & JUMLAH & $\mathbf{1 4 . 0 0 0 . 0 0 0 , -}$ \\
\hline & & & \\
\hline
\end{tabular}

\section{DAFTAR PUSTAKA}

Aida Idris, 1983, Cara-cara Belajar yang Efisien, dalam Materi Dasar Program Bimbingan dan Konseling untuk Perguruan Tinggi; Psikologi Belajar, Proyek Normalisasi Kehidupan Kampus, Direktorat Jenderal Pendidikan Tinggi, Departemen Pendidikan dan Kebudayaan, Jakarta.

Amir Hamzah, Sulaeman, 1970, Media Audio-Visual untuk Pengajaran, Penerangan dan Penyuluhan, P.T. Gramedia, Jakarta.

Arsyad, Azhar, 2002, Media Pembelajaran, Rajafindo Persada, Jakarta.
Dale, E., Audiovisual Method in Teaching (Third Edition), The Dryden Press, Holt, Renehart and Winson, Inc, New York.

Maman Achdiat, dkk.,1980, Teori Belajar Mengajar dan Aplikasinya dalam Program Belajar Mengajar, Proyek Pengembangan Pendidikan Guru (P3G), Departemen Pendidikan dan Kebudayaan, Jakarta.

Oemar Hamalik, 1982, Media Pendidikan, Alumni, Bandung,

http://www.perencanakeuangan.com/files/ Faktor Penghasilan.html diambil tanggal 4/30/ 2012 jam 11:26 